\title{
Biologia da traça das crucíferas, Plutella xylostella Linnaeus (Lepidoptera, Yponomeutidae), sob condições controladas de temperatura, e parasitóides associados. Part III. Estudo sobre a biologia de Apanteles piceotrichosus (Blanchard) (Hymenoptera, Braconidae): análise do efeito de endocruzamento
}

\author{
Rafaelle R. Gonçalves \& Rocco A. Di Mare \\ Departamento de Biologia, Centro de Ciências Naturais e Exatas, Universidade Federal de Santa Maria. Campus \\ Universitário, Faixa de Camobi km 9, 97119-900 Santa Maria, Rio Grande do Sul, Brasil. E-mail: rafaellerg@brturbo.com.br; \\ ram13@terra.com.br
}

\begin{abstract}
Biology of crucifer moth, Plutella xylostella Linnaeus (Lepidoptera, Yponomeutidae), under controlled temperature conditions, and parasitoids associated. Part III. Study on the biology of Apanteles piceotrichosus (Blanchard) (Hymenoptera, Braconidae): analysis of the inbreeding effect. The inbreeding in natural populations results in a loss in the genetic variability that can influence juvenile and adult mortality, the size, viability and fertility of the offspring, as well as the individuals morphology. Apanteles piceotrichosus (Blanchard, 1943) (Hymenoptera, Braconidae) is a Plutella xylostella Linnaeus,1758 parasitoid (Lepidoptera, Yponomeutidae) that has been attracting a lot of attention to a biocontrol purpose, because it can be used as agent of biological control. For the creation and liberation of parasitoids are necessary studies on its biology. The objective of the present study was carried out to examine the inbreeding effect on the mortality, longevity and sexual ratio of $A$. piceotrichosus. The parasitoid attack rate was also observed. The crossings, scheduled, were made starting from individuals collected in field and breed in laboratory under controlled conditions. Were not observed significant differences in mortality and longevity of $A$. piceotrichosus, as well as in the rate of attack of the parasitoid on the host. The sexual ratio showed significant differences among the control and inbreeding group. Even so differences were not observed inside of the inbreeding group.
\end{abstract}

KEY WORDS. Insects, longevity, mortality, parasitoids, sexual ratio.

RESUMO. O endocruzamento em populações naturais resulta em uma perda na variabilidade genética que pode influenciar, a mortalidade juvenil e adulta, o tamanho, a viabilidade e fertilidade da prole, bem como a morfologia dos indivíduos. Apanteles piceotrichosus (Blanchard, 1943) (Hymenoptera, Braconidae) é um parasitóide de Plutella xylostella Linnaeus,1758 (Lepidoptera, Yponomeutidae) que tem atraído muita atenção com o propósito de biocontrole, pois pode ser utilizado como agente de controle biológico. Para a criação e liberação destes indivíduos são necessários estudos sobre a sua biologia. $O$ objetivo do presente estudo foi examinar o efeito do endocruzamento sobre a mortalidade, longevidade e proporção sexual de $A$. piceotrichosus. Também foi observada a taxa de ataque do parasitóide sobre o hospedeiro. Foram realizados cruzamentos programados, a partir de indivíduos coletados em campo e criados em laboratório sob condições controladas. Não foram observadas diferenças significantes na mortalidade e na longevidade de $A$. piceotrichosus, bem como na taxa de ataque do parasitóide sobre o hospedeiro. A proporção sexual apresentou diferenças significantes entre o grupo controle e o endocruzado,entretanto não foram observadas diferenças dentro do grupo endocruzados.

PALAVRAS CHAVE. Insetos, longevidade, mortalidade, parasitoidismo, proporção sexual.

Nas populações naturais existem dois tipos de seleção natural: um que elimina a variação genética das populações naturais e outro que promove essa variação. O endocruzamento nessas populações resulta em uma perda na variabilidade genética que pode influenciar o tamanho, a viabilidade e fertilidade da prole, a mortalidade juvenil e adulta bem como a morfologia dos indivíduos. A baixa variabilidade genética pode acarretar numa redução da capacidade de adaptação em longo prazo (LANDE \& Barrowclough 1987, Cassel et al. 2001).

Apanteles piceotrichosus (Blanchard, 1943) é um parasitóide que ataca as populações de larvas de segundo estádio de Plutella xylostella Linnaeus, 1758, que tem atraído atenção como agen-

Revista Brasileira de Zoologia 22 (3): 806-809, setembro 2005 


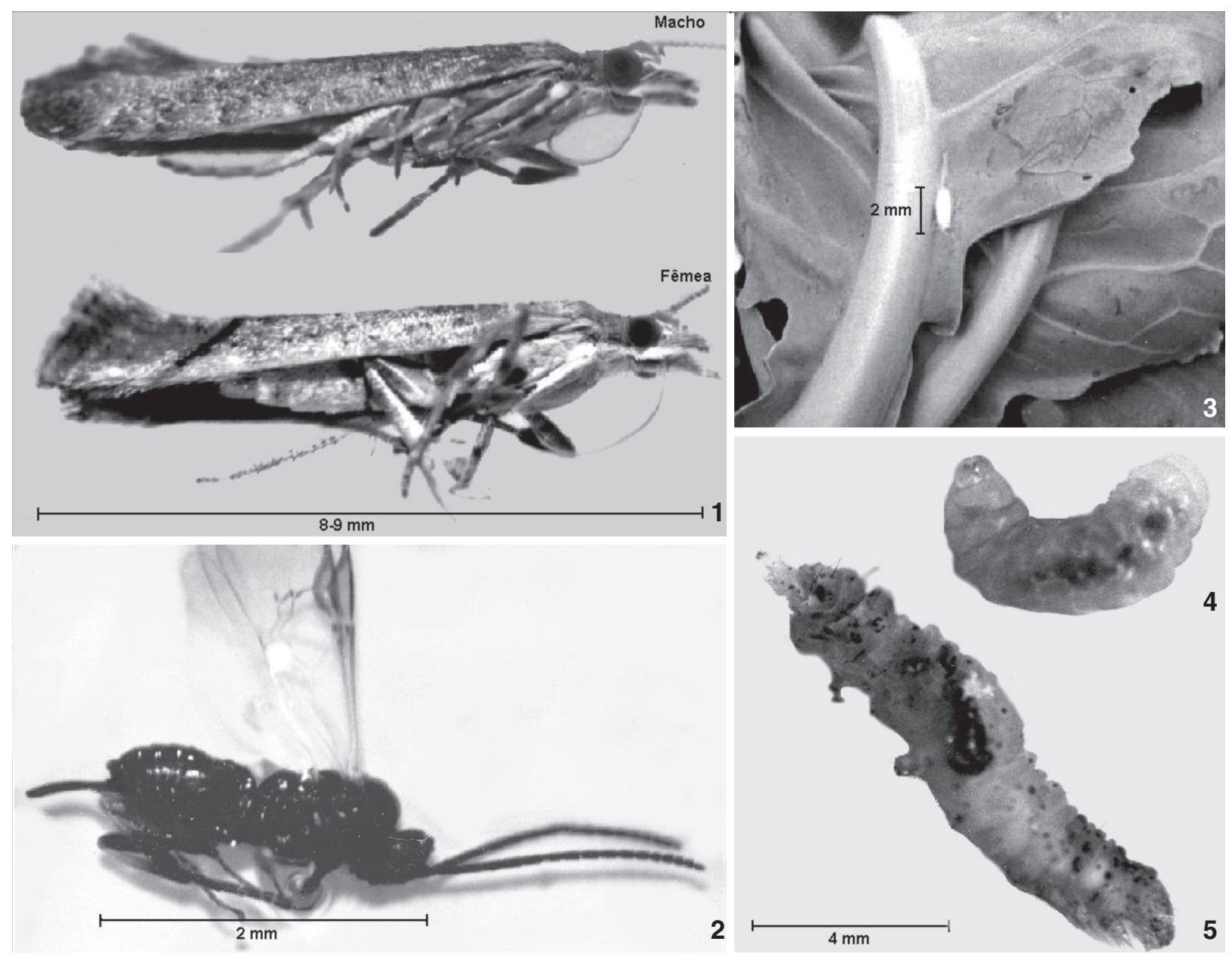

Figuras 1-5. (1) Macho e fêmea de Plutella xylostella; (2) fêmea de Apanteles piceotrichosus; (3) casulo de Apanteles piceotrichosus; (4) larva de Apanteles piceotrichosus; (5) larva de Plutella xylostella parasitada por Apanteles piceotrichosus.

te de controle biológico. Plutella xylostella (Fig. 1) é uma praga de culturas de brássicas que causa danos consideráveis no Brasil (Bondar 1928) e no mundo (TALEKAR \& SHeLton 1993).

Os parasitóides podem ser elementos importantes para o controle natural de pragas, sendo assim biocontroladores das populações de seus hospedeiros (Hassell 1986). Para a criação e liberação em massa de parasitóides é necessária a realização de estudos sobre a sua biologia, pois somente desta forma pode-se realizar o controle biológico de pragas (PARRA 2000).

O objetivo do presente estudo foi examinar o efeito do endocruzamento sobre a mortalidade, longevidade, proporção sexual e taxa de parasitoidismo de A. piceotrichosus (Fig. 2) sobre P. xylostella.

\section{MATERIAL E MÉTODOS}

Em culturas de couve (Brassica oleracea) em Santa Maria, Rio Grande do Sul, foram coletadas larvas e pupas de P. xylostella e casulos de A. piceotrichosus (Fig. 3), no período de dezembro de 1997 a maio de 1998 .

Os indivíduos coletados foram conduzidos ao Laboratório de Biologia Evolutiva do Departamento de Biologia da UFSM. O transporte foi realizado em potes plásticos transparentes atóxicos, utilizados também para a sua criação. Todos os indivíduos foram mantidos sob condições de laboratório de $25^{\circ} \mathrm{C} \pm 1{ }^{\circ} \mathrm{C}$, umidade relativa entre $60 \%$ e $70 \%$ e fotoperíodo de $14 \mathrm{~h} / \mathrm{luz}$.

As larvas de $P$. xylostella foram alimentadas com couve e os adultos de P. xylostella e A. piceotrichosus com uma solução de mel de abelha e água destilada na proporção 1:4 embebida em mechas de algodão colocadas nas tampas dos potes.

Em laboratório, foram realizados trinta e três cruzamentos com indivíduos selecionados de $A$. piceotrichosus. A quantidade de cruzamentos para cada coeficientes de endocruzamento (F) foi: doze com F = 0; um com F = 0,06; um com F = 0,08; um com $\mathrm{F}=0,13$; sete com $\mathrm{F}=0,25$; quatro com $\mathrm{F}=0,28$; dois com $\mathrm{F}=$ 0,31 ; e cinco com $\mathrm{F}=0,35$. Os cruzamentos foram realizados

Revista Brasileira de Zoologia 22 (3): 806-809, setembro 2005 

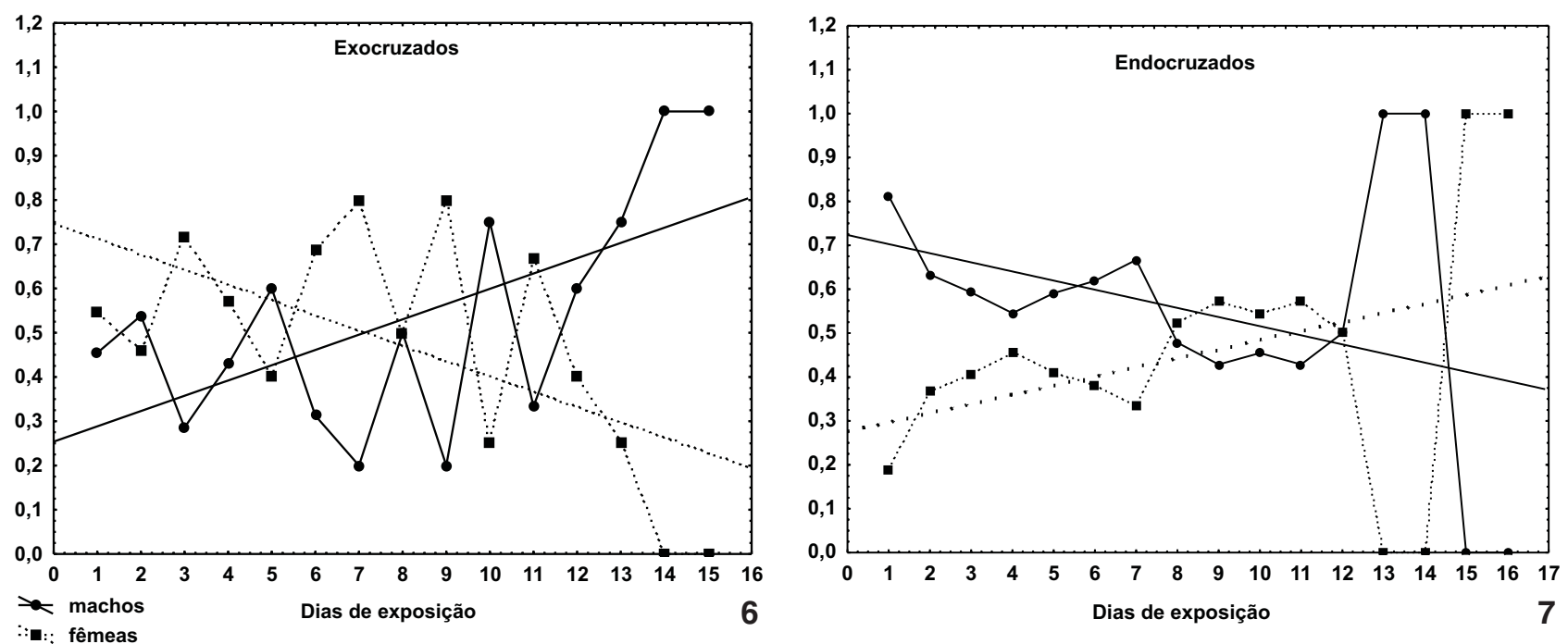

Figuras 6-7. Proporção sexual diária e respectivas linhas de regressão dos exocruzamentos (6) e endocruzamentos (7).

com fêmeas virgens individualizadas e machos selecionados, ambos recém emergidos. Cada casal foi colocado em pote plástico transparente atóxico. Ao casal eram expostas diariamente, em folhas de couve, cinco larvas de $P$. xylostella em segundo estádio. Após 24 horas as larvas eram transferidas para outro pote e substituídas por outras cinco larvas, repetindo o processo diariamente até a morte da fêmea parasitóide. As larvas expostas aos casais foram alimentadas com couve até elas empuparem ou até a emergência de casulos do parasitóide (Figs 4 e 5). Os casulos que surgiram das larvas expostas aos parasitóides eram isolados até a eclosão dos adultos, que eram individualizados e alimentados até a sua morte. Foram obtidos dos cruzamentos 343 indivíduos, sendo 133 dos exocruzamentos e 210 dos endocruzamentos.

\section{RESULTADOS E DISCUSSÃO}

A análise da proporção sexual (machos/total) (Tab. I) demonstrou que as diferenças são estatisticamente significantes $\left(\mathrm{F}_{(1,31)}=5,41 ; \mathrm{p}<0,0267\right)$, ocorrendo um favorecimento a proporção de machos nos endocruzados $(0,61 \pm 0,34)$, o que não ocorreu nos controles $(0,45 \pm 0,31)$. Estes resultados sugerem que as fêmeas de $A$. piceotrichosus podem controlar a proporção sexual, pois estes indivíduos apresentam sistema haplo-diplóide, e desta maneira evitariam o endocruzamento na população. A análise da proporção sexual diária dos cruzamentos controles e dos endocruzados (Figs 6 e 7), mostra que no grupo exocruzado, as fêmeas produziram uma maior quantidade de fêmeas nos primeiros dias de postura (do primeiro ao sexto dia), diminuindo gradualmente até o $15^{\circ}$ dia, quando cessavam a oviposição (Fig. 6). Porém nos endocruzados os valores observados para a proporção sexual diária (Fig. 7) embora apresentem um coeficiente de regressão negativo mostram uma alternância entre a proporção de machos e fêmeas. A proporção de machos foi mais eleva-
Tabela I. Média e desvio padrão da porcentagem de casulos eclodidos, proporção sexual, duração dos estágios imaturos e longevidade estimada nos exocruzamentos e endocruzamentos realizados com Apanteles piceotrichosus, em condições controladas de laboratório.

\begin{tabular}{lrrr}
\hline & Exocruzados & Endocruzados \\
\hline Casulos eclodidos (\%) & $85,00 \pm 11,06$ & $78,30 \pm 14,94$ \\
Proporção sexual (machos/total) & $0,45 \pm$ & 0,31 & $0,61 \pm 0,34$ \\
Duração estágios imaturos (dias) & $14,57 \pm 2,27$ & $15,52 \pm 1,34$ \\
Longevidade média (dias) & $12,71 \pm$ & 6,65 & $13,39 \pm 7,08$ \\
Longevidade máxima (dias) & 30 & 34 \\
\hline
\end{tabular}

da entre o primeiro e o sétimo dia e entre o $13^{\circ}$ e o $14^{\circ}$. Na literatura consultada não existem registros do efeito do endocruzamento neste grupo. Esta inversão na produção sexual dos indivíduos sugere que as fêmeas endocruzadas produzem um maior número de machos para diminuir os níveis de endocruzamento de uma população. Entretanto, segundo o trabalho de Hurst \& JigGINS (2000), estes desvios poderiam estar associados a ação de bactérias herdadas pelas fêmeas ("male-killing bacteria"), que seriam responsáveis pela mortalidade dos machos na progênie. De acordo com estes autores um aumento na taxa de endocruzamento das fêmeas diminuiria a prevalência destas bactérias, aumentando a proporção de machos. O que poderia explicar o aumento na proporção de machos no início dos endocruzamentos. Por outro lado, o aumento de recursos obtido pelas fêmeas, devido a redução da competição, aumentaria a prevalência das bactérias ao longo da vida das fêmeas, explicando assim a diminuição na proporção dos machos ao longo dos cruzamentos.

A porcentagem de casulos eclodidos (Tab. I) entre os exocruzados $(85 \pm 11,06)$ e os endocruzados $(78,30 \pm 14,94)$ 
não mostraram diferenças significativas $\left(\mathrm{F}_{(1,31)}=1,43 ; \mathrm{p}<\right.$ $0,2408)$, demonstrando que o endocruzamento não influência a mortalidade dos indivíduos.

A duração média dos estágios imaturos, da exposição até a eclosão dos adultos (Tab. I), entre a prole exocruzada $(14,57 \pm$ $2,27)$ e a endocruzada $(15,52 \pm 1,34)$ apresentou diferenças estatisticamente significantes $\left(\mathrm{F}_{(1,33)}=18,60 ; \mathrm{p}<0,0001\right)$. Embora, a longevidade média dos adultos provenientes dos exocruzamentos $(12,71 \pm 6,65)$ seja menor que dos endocruzamentos $(13,39 \pm$ $7,08)$ quando testadas não são estatisticamente significantes. A longevidade máxima observada nos exocruzados foi de 30 dias e nos endocruzados foi de 34 dias.

\section{CONCLUSÕES}

Os resultados mostram que no endocruzamento há um favorecimento na proporção de machos, ao contrário do que ocorre no exocruzamento. A taxa de eclosão dos casulos não difere entre os endocruzados e os exocruzados, mostrando que o endocruzamento não influencia na mortalidade deste estágio. Entretanto, os valores de duração dos estádios imaturos, da exposição até a eclosão de adultos, são significativamente diferentes entre os dois grupos. As diferenças na longevidade dos adultos entre os dois grupos não são significativas.

\section{AGRADECIMENTOS}

A FAPERGS pelo incentivo financeiro e bolsa de iniciação científica concedida. Ao FIPE pela bolsa de iniciação científica.

\section{REFERÊNCIAS BIBLIOGRÁFICAS}

Bondar, G. 1928. Uma séria praga do repolho na Bahia Plutella maculipennis Curtis. Chácaras e Quintais, São Paulo, 38 (6): 602.

Cassel, A.; J. Windig; S. Nylin \& C. Wiklund. 2001. Effects of Population Size and Food Stress on Fitness-Related Characters in the Scarce Heath, a Rare Butterfly in Western Europe. Conservation Biology, Boston, 15 (6): 1667.

Hassel, M. P. 1986. Parasitoids and population regulation, p. 201-224. In: J. WaAge \& D. Greathead (Eds). Insect Parasitoids. London, Academic Press, 389p.

Hurst, G. D.D. \& F.M. Jiggins. 2000. Male-Killing Bacteria in Insects: Mechanisms, Incidence, and Implications. Emerging Infectious Diseases, Atlanta, 6 (4): 329-360.

LANDE, R. \& G.F. BarrowClough. 1987. Effective population size, genetic variation, and their use in population management, p. 87-123. In: M.E. Soule (Ed.). Viable populations for conservation. Cambridge, Cambridge University Press.

PARRA, J.R.P. 2000. O controle biológico e o manejo de pragas: passado presente e futuro, p. 59-70. In: J.C. GuEDEs; I.D. CosTA; E. Castiglioni (Eds). Bases e Técnicas do Manejo de Insetos. Santa Maria, Palotti, 234p.

Talekar, N.S. \& A.M. Shelton. 1993. Biology, ecology and management of the diamondback moth. Annual Review of Entomology, Palo Alto, 38: 275-301.

Recebido em 15.II.2005; aceito em 29.VIII.2005. 